\title{
The future of dermatopathology
}

\author{
A Neil Crowson \\ Departments of Dermatology, Pathology, and Surgery, University of Oklahoma and Regional Medical \\ Laboratory, St John Medical Center, Tulsa, OK, USA
}

\begin{abstract}
Of the major issues that dermatopathology will face in the immediate future, two powerful challenges loom large. The first is the application of novel nondestructive imaging technologies to in vivo diagnosis in humans. The second is the application of molecular technologies to a diagnostic arena which formerly belonged exclusively to the light microscopist. The first to be considered in this context is the application of near infrared spectroscopy to the noninvasive in vivo diagnosis of neoplastic skin disease. The second will be a discussion of application, methodology and the current state of the art in microarray technologies as they apply to neoplastic dermatopathology and, in particular, the diagnosis and prognostication of melanoma.

Modern Pathology (2006) 19, S155-S163. doi:10.1038/modpathol.3800513
\end{abstract}

Keywords: in vivo microscope; tissue microarray; basal cell carcinoma; infrared spectroscopy

\section{Noninvasive assessment of skin lesions by near infrared (IR) spectroscopy}

In the late 1990s, working with Dr Laura McIntosh and colleagues at the National Research Council of Canada, the University of Manitoba, Central Medical Laboratories and the Misericordia General Hospital in Winnipeg, Canada, we designed and patented a noninvasive tool for the diagnosis of skin tumors using visible and near IR spectroscopy in the 400$2500 \mathrm{~nm}$ size wavelength range $^{1-5}$ Initially, we excised neoplasms, and processed them in the fresh state with sections for formaldehyde fixation and paraffin embedding matched to tissue elements snap frozen in liquid nitrogen and stored at $-80^{\circ} \mathrm{F}$. Thick sections from the frozen tissue elements were interrogated by mid-IR wavelength light (Figure 1). The transmitted light generated significant spectral differences; water, hemoglobin, cytochromes, lipids and proteins all absorb light at specific frequencies (Figure 2). In particular, the mid-IR range is rich with information about proteins including in the context of collagen and RNA. When analyzed by a sophisticated leave-one-out hierarchical classification algorithm, distinction between microanatomic compartments of the skin could be made (Figure 3). Using this methodology, we were able with an accuracy of $90-95 \%$ to distinguish basal cell carcinoma (BCC) from melanocytic nevi, seborrheic

Correspondence: Dr AN Crowson, MD, Regional Medical Laboratory, St John Medical Center, 1923 S. Utica Street, Tulsa, OK 74114-4109, USA.

E-mail: ncrowson@sjmc.org

Received 23 September 2005; accepted 28 September 2005 keratoses and squamous cell carcinomata in vitro. Melanocytic nevi could be subdivided into banal vs dysplastic nevi based upon their spectral differences and melanomas could be separately recognized as well. Furthermore, the different types of lesion were shown to have distinct mid-IR signatures when compared to adjacent normal epidermal and dermal compartments.

Unfortunately, the diagnostic potential of mid-IR spectroscopy for in vivo applications is limited, as complete absorption of mid-IR light occurs with samples greater than $10-15 \mu \mathrm{m}$ in thickness. In contrast, near-IR light scatters to a much greater extent than it absorbs and in consequence, tissues are relatively transparent in the near-IR region which permits the examination of larger tissue volumes and led to the creation of an in vivo nearIR device (Figure 4). Between 650 and $900 \mathrm{~nm}$ proved ideal and is called the 'biological window' for in vivo imaging because there is less absorption in this spectral range. This in turn may partly reflect the metabolic 'activity' and oxygenation status of the tissue.

Near-IR light was brought from a spectrometer to the skin via a fiberoptic cable (Figure 4). Light penetrated the skin. As in the in vitro experiments, water, hemoglobin, cytochromes, lipids and proteins all absorb light at specific frequencies; the remainder was scattered by the skin with some light being back-scattered into the fiberoptic probe. The light was collected by the probe and transmitted back to the spectrometer for analysis and a plot of the amount of light absorbed at each wavelength was computed. The latter represents the near-IR spectrum. These data could be measured rapidly 


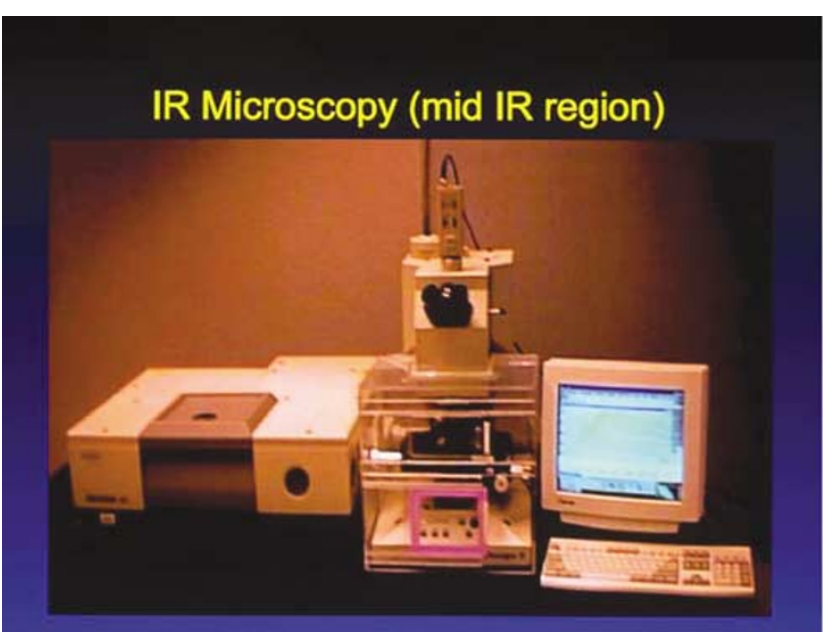

Figure 1 Mid-infrared spectroscopy system. For in vitro spectroscopic analysis, thick cryostat sections are placed in the spectroscopy specimen chamber (left). The territory of spectroscopic analysis is controlled robotically and matched to a hematoxylinand eosin-stained frozen section placed on the microscope stage (middle). A computer station (right) completes the assembly.

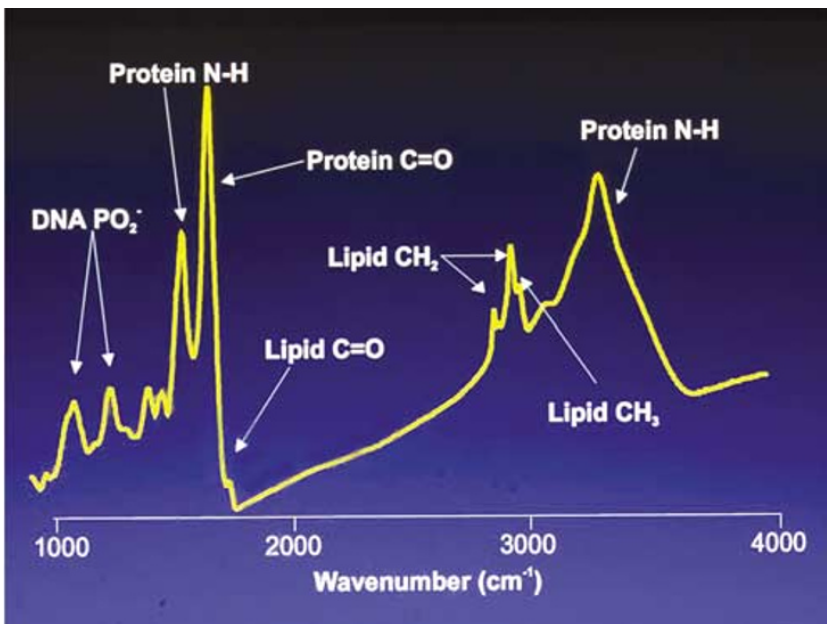

Figure 2 Spectrograph of frozen skin tissue. Proteins, phosphates, carbohydrates and lipids all generate a different absorbance and reflectance depending upon the wavelength of the incident light from the mid-infrared spectrum.

with no tissue destruction and without the obtaining of a biopsy sample at the time of interrogation. Thus, this was an entirely noninvasive methodology. Immediately, the tissue element under study was biopsied or excised for pathological analysis. The information generated by spectroscopic analysis was analyzed statistically through paired T-tests to identify significant differences between lesional and control normal skin spectra. These $P$-values were then plotted against wavelength and the mean control spectrum then subtracted from each mean lesion spectrum in a pair-wise fashion to demonstrate differences between spectra. Based upon these

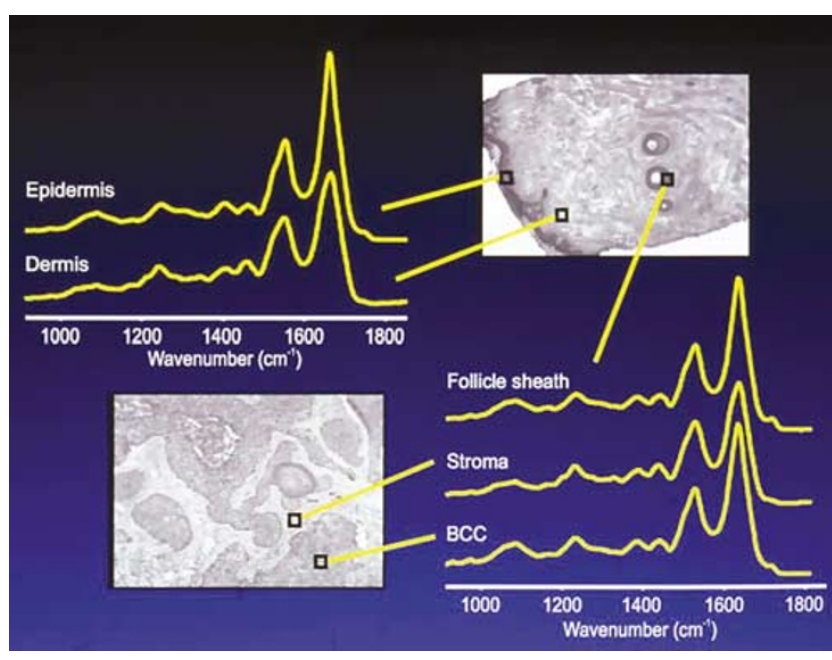

Figure 3 Spectroscopic analysis of microanatomic components of the skin. Although they appear similar to the naked human eye, the computer can reliably distinguish the spectroscopic differences between epidermis, dermis, hair follicle sheath, stroma and basal cell carcinoma.

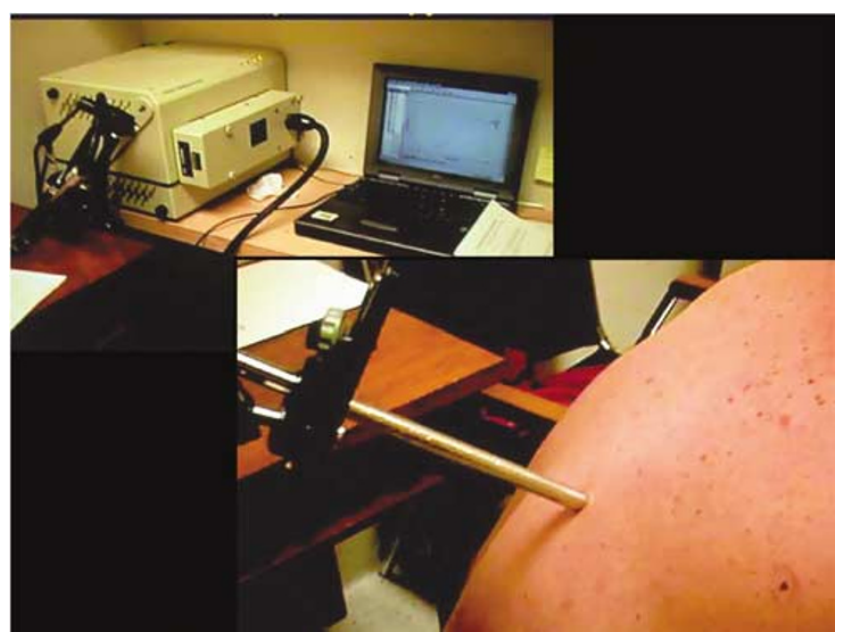

Figure 4 In vivo device for near-infrared spectroscopy of skin lesions. Through an afferent fiber optic device, near infrared wavelength light is projected directly onto a target lesion on the back of a man with multiple dysplastic nevi. The reflected light is returned via an efferent fiber optic lead to the spectography device and the spectra stored to the hard disk of a notepad computer

results a discrete number of wavelengths were selected to perform repeated measured analysis of variance (ANOVA) which suggested that the spectra were highly reproducible. Multivariant statistics, in particular Fisher's least significant difference showed various significant intergroup differences between the types of lesion analyzed. Linear discriminate analysis (LDA) using the 'leave one out' crossvalidation strategy ${ }^{6}$ was applied to determine the likelihood of a spectrum belonging to each class and spectra were then allocated to the class to 
which they fit most closely. Lesions studied by the LDA methodology included: (1) Dysplastic vs banal nevi; (2) Dysplastic nevi vs lentigines; (3) Actinic keratoses vs lentigines; (4) Actinic keratoses vs seborrheic keratoses; (5) BCC vs seborrheic keratoses; (6) BCC vs banal nevi; and, (7) Dysplastic nevi vs seborrheic keratoses. The ability to separate dysplastic from banal nevi was demonstrated at the $97.7 \%$ level (vs a level of $89.6 \%$ by the clinician). ${ }^{4,5}$ In contrast, the clinician was able to distinguish dysplastic nevi from actinic lentigines with $100 \%$ accuracy vs only $92.0 \%$ using the LDA methodology. The most discrepant result was the distinction of dysplastic nevi vs seborrheic keratoses, carried out with $100 \%$ accuracy by an experienced clinician vs only $72.4 \%$ accuracy by near-IR spectroscopy.

We demonstrated that near-IR spectroscopy may form the basis of a clinical methodology to diagnose skin lesions in a rapid, simple and noninvasive fashion. Measurements proved accurate and reproducible and the technology is noninvasive and nondestructive. Further advances in the application of near-IR spectroscopy to skin lesions may provide complementary data to clinical examination and histopathology.

\section{Molecular adjuncts to diagnosis: the microarray}

The astonishing success of the Human Genome Project in identifying over 25000 structurally unique genes distributed over 3.2 billion base pairs of human DNA has generated a new level of activity directed at unraveling the molecular basis of neoplasia. ${ }^{7-9}$ Novel molecular methodologies are now being employed which are complementary to traditional microscopy of formalin-fixed tissue.

Immunohistochemical analysis performed on paraffin-embedded tissue has since the early 1980s been used to detect the protein products of gene expression and thus to predict the malignant phenotype or, more commonly, to confirm the histogenesis of a particular neoplasm. Reverse transcriptase polymerase chain reaction (RT-PCR) methodologies detect mRNA in tissue to provide similar and complementary information, but typically are employed to asses the expression of one, or at most a few, genes at one time. A novel scientific approach has evolved that employs microarray technology to assess biomolecules in high-throughput analytical systems. Those microarray technologies currently utilized are broadly classified as representing complementary DNA (cDNA) microarrays, oligonucleotide arrays, protein microarrays and tissue microarrays. ${ }^{10}$ The information derived from cDNA microarray studies permits meta-analysis of huge quantities of information, which can be correlated mathematically for the extraction of the maximum amount of scientific information. ${ }^{11} \mathrm{cDNA}$ is obtained from in vitro reverse transcription of total RNA and reflects all of the genes in a tissue sample save for the spliced introns (Figure 5). The biological sample which is the target of microarray analysis typically comprises $10-40 \mu \mathrm{g}$ of high-quality RNA. Such a sample would be extracted from a tissue element roughly $100 \mathrm{~mm}^{3}$ in size (ie a $4 \mathrm{~mm}$ punch biopsy). ${ }^{12}$ In our experience, tissue samples snap frozen in liquid nitrogen and then stored for 5 years at $-80^{\circ} \mathrm{F}$ proved noninformative due to RNA degradation. It has proven far better to extract the RNA from the tissue sample in the fresh state at the bench immediately adjacent to the site where the biopsy or excision is performed. There are, in addition, commercial products designed to preserve RNA for transport over a $24-48 \mathrm{~h}$ period prior to extraction. The purified RNA sample is then reverse transcribed into cDNA to prepare for creation of the microarray.

The cDNA microarray is a miniature display of large numbers of DNA sequences on a solid support system, either a microchip or a slide. The methodology employed to create a cDNA microarray involves the generation of cDNA copies from mRNA, optimally derived from fresh tumor samples, and synthesized in vitro with fluorescent-labeled nucleotides which are robotically hybridized into the array. Thousands of unique cDNA probes can be applied per square centimeter of slide or microchip array (Figure 6). Glass is preferable as it enables the use of small reaction volumes, permitting a greater number of probes to be applied in a smaller space with low autofluorescence, allowing the simultaneous application of paired fluorophores to a single sample. ${ }^{13,14}$ Oligonucleotides of cDNA, typically 20-25 base pairs long, are spotted mechanically onto a silane-coated slide or are synthesized in loco. ${ }^{15}$

For analysis using a cDNA microarray it was formerly imperative to employ specific sets of tissue-appropriate cDNA probes generated from the mRNA derived from relevant clones. For cells of melanocyte lineage, the expressed sequenced tag database (dbEST) for neural crest-derived melanocytic cDNA sets was created. ${ }^{16}$ The Stanford University microarray database lists, for example, specific sets of tissue-appropriate cDNA for use in various human cancers and is accessible through their website (http://genome-www.stanford.edu/ microarray). ${ }^{17}$ In current applications, it is now possible to assess gene expression on a genomewide scale in a single tissue sample, a process referred to as structural genomics. ${ }^{18}$

Microarrays are analyzed using complex biochemical-optical systems that employ analytical computer technologies including neural nets and hierarchical data analysis and processing to decode the complex array of data generated. ${ }^{19}$ This technology provides for rapid identification of amplification of genes. ${ }^{20}$ Amplification of expression can be detected at a level of only five times above 


\section{Microarrays}

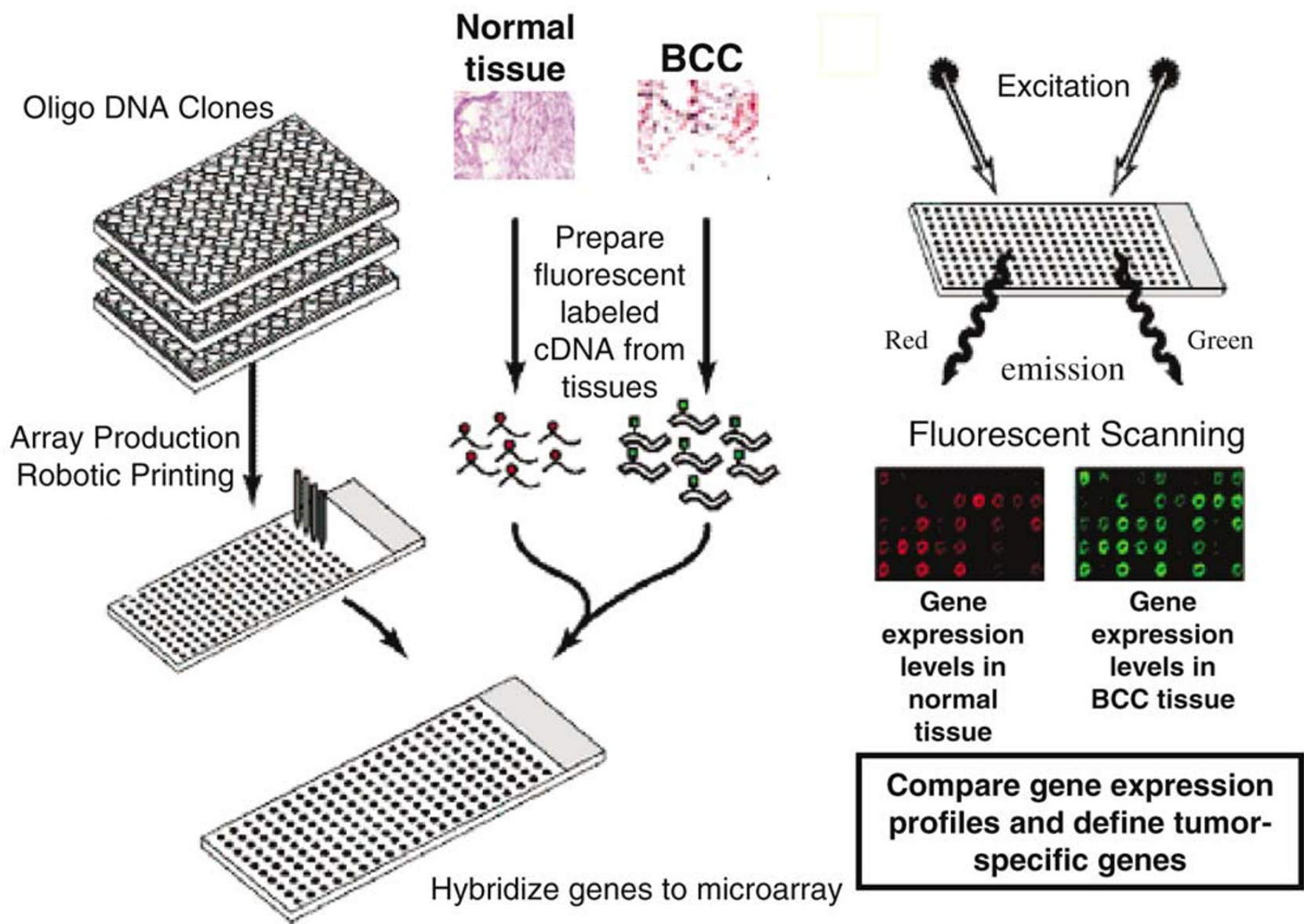

Figure 5 Complementary DNA (cDNA) microarray. RNA is extracted from the neoplasm (in this case a basal cell carcinoma) and adjacent normal tissue; from the RNA, cDNA is prepared by in vitro reverse transcription of the total RNA extracted from fresh tissue. The cDNA is then hybridized robotically into a glass slide array with green and red fluorophores. These fluorophores are excited by fluorescent light and the red and green wavelength emissions are captured and quantitated by an optical scanner.

\section{OMRF Microarrays}

"Genome-scale" human chips Human 21,324 genes/chip

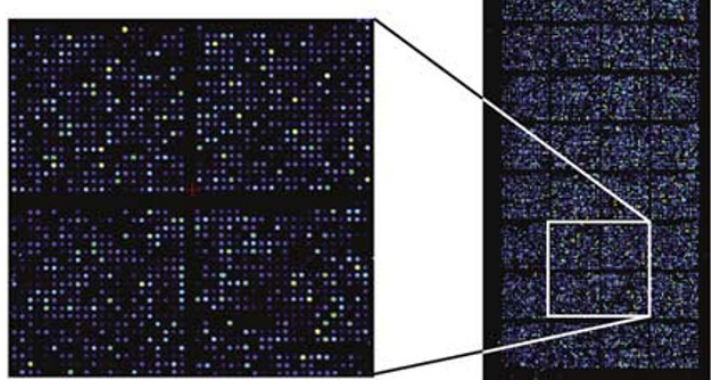

Figure 6 At the Oklahoma Medical Research Foundation (OMRF) are employed genome scale human chips with 21324 genes per chip. Illustrated is an actual slide bearing cDNA from over 21000 human genes. background. A single mRNA species can be detected from among 500000 different mRNAs. With respect to genome-wide microarray, specific software permits the measurement of expression and its intensity vs control tissues (Figure 7) while other tools utilize clustering algorithms to identify clusters of genes with similar patterns of expression and/or linked functions. In an unpublished study of BCC, we analyzed five tumors and nearby normal control skin from the same patients in order to identify the upregulation of a group of genes that relate to the actin filament/cell surface attachment plaque assembly system, which is known to impact cell motility (Figures 8 and 9). Cluster identification software alerted us to the functional linkage between several of these genes (Figure 10).

One group analyzed melanoma samples with an array of 7000 discrete genes, and thereby identify a distinct malignant melanoma subset capable of producing primitive tubular networks in vivo that correlate to aggressive biological behavior. ${ }^{21}$ The 


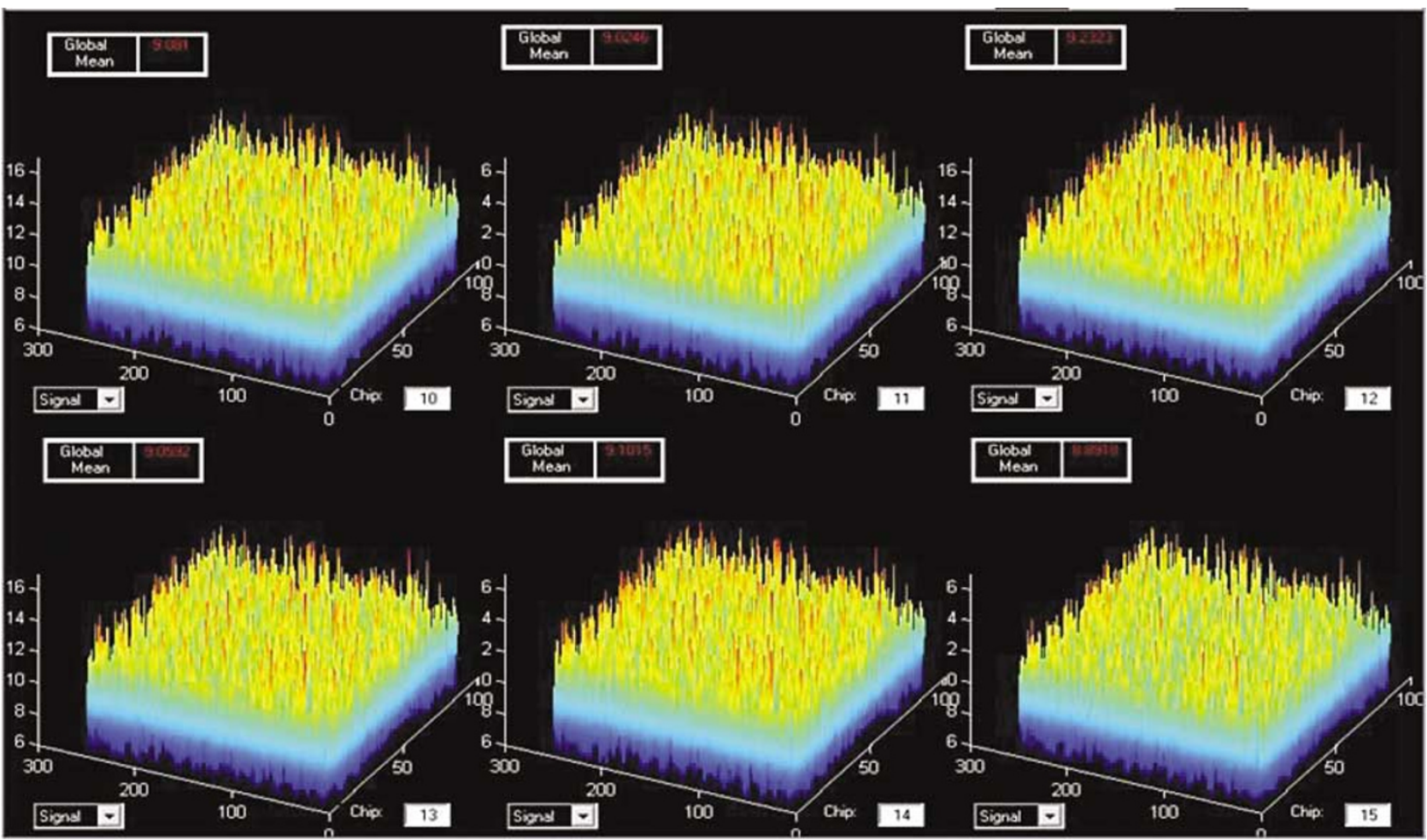

Figure 7 cDNA microarray: optical output. The height of the individual spikes of green or red fluorescence correspond to the differential levels of gene transcription.

authors proved that global transcript analysis could be applied to malignant melanoma cell lines to identify previously unrecognizable clonal subsets. $\mathrm{Su}$ et $\mathrm{al}^{22}$ analyzed the expression of 3317 genes in three different melanoma cell lines, analyzed in pairs by cDNA microarray technology, to identify specific tumor suppressor genes including the Cx43 suppressor gene, monocyte chemotactic protein-1 (suppressor) and the cystein proteinase P32- $\alpha$ gene responsible for apoptosis. Transfection of the Cx43 gene from chromosome 6q21-23 suppressed anchorage-independent growth of a melanoma cell line, proving that the ability to alter cellular phenotype in concert with global gene expression profiling enabled the identification of previously unrecognized tumor suppressor genes. ${ }^{22}$ Other groups have used microarrays to analyze the gene expression profile of melanoma $v S$ dysplastic nevi ${ }^{23}$ or to determine which genes are operative in the transformation from localized to metastatic melanoma. ${ }^{24-28}$ As expected, the progression from radial to vertical growth phase is associated with loss of cell cycle regulatory control. For example, cyclin D1 is expressed in radial growth phase melanoma and is lost in progression to vertical growth phase neoplasms, while p16 (INK4A) and p27 (KIP1) expression are diminished in advanced melanoma. ${ }^{29}$ Another territory of interest is those genes which determine the regulation of the immune response to melanoma. ${ }^{30}$ Other novel genes that have been detected that were not hitherto implicated in melanomagenesis include WNT5A, a proto-oncogene involved in cell motility; ${ }^{21}$ confirmatory application of an antibody that inactivates the wnt5a protein product, termed 'Frizzled-5', arrests the effects of wnt5a. ${ }^{31}$ In addition to WNT5A, other genes are implicated in the acquisition of cell motility and angiogenesis. ${ }^{25,26,32-34}$ Hypoxia-inducible genes such as Cyr61 have shown to be constitutively upregulated in late stage melanoma. ${ }^{35}$

Complementary to cDNA microarray is the tissue microarray. The latter involves the performance of a core sample of a block of paraffin-embedded tissue and relocation of the tissue core to an array block which is then sectioned to generate $0.5-0.6 \mathrm{~mm}$ crosssections; hundreds of cores from different neoplasms or tissues are then placed on a single slide. This slide-based array is then analyzed with conventional immunohistochemical reagents and is thus in a sense analogous to the protein array methodologies, at least from the standpoint of detecting the protein products of gene expression in tissue. ${ }^{36}$ This technology likely will prove amenable to application to cytologic preparations also. ${ }^{10}$ The tissue microarray can thus be used to confirm the expression of genes in known samples of formalin-fixed tumors.

Apoptotic pathways are an area of intense interest in melanoma biology. ${ }^{37}$ Genome-wide scans may be used to identify likely gene candidates for more 


\begin{tabular}{|c|c|c|c|c|c|}
\hline $\begin{array}{c}\text { GenBank } \\
\text { Accession }\end{array}$ & $\begin{array}{l}\text { Gene } \\
\text { Symbol }\end{array}$ & Description & $\begin{array}{l}\text { Average } \\
\text { of } \\
\text { Tumor }\end{array}$ & $\begin{array}{c}\text { Average } \\
\text { of } \\
\text { Normal }\end{array}$ & Ratio \\
\hline AF111848 & ACTB & Actin, beta & 214.07 & 87.15 & 2.46 \\
\hline NM_021631 & FKSG2 & Apoptosis inhibitor & 195.96 & 74.23 & 2.64 \\
\hline NM_000090 & COL3A1 & $\begin{array}{c}\text { Collagen, type III, alpha } 1 \\
\text { (Ehlers-Danlos syndrome type } \\
\text { IV, autosomal dominant) }\end{array}$ & 77.63 & 22.77 & 3.41 \\
\hline NM_005607 & PTK2 & PTK2 protein tyrosine kinase 2 & 150.04 & 66.60 & 2.25 \\
\hline NM_003118 & SPARC & $\begin{array}{l}\text { Secreted protein, acidic, } \\
\text { cysteine-rich (osteonectin) }\end{array}$ & 75.27 & 24.30 & 3.10 \\
\hline NM_021103 & TMSB10 & Thymosin, beta 10 & 112.37 & 31.14 & 3.61 \\
\hline AK055976 & TMSB4X & $\begin{array}{l}\text { Thymosin, beta } 4, \mathrm{X} \\
\text { chromosome }\end{array}$ & 180.56 & 40.81 & 4.42 \\
\hline AK027071 & TSC22 & $\begin{array}{c}\text { Transforming growth factor } \\
\text { beta-stimulated protein TSC- } \\
22\end{array}$ & 10.78 & 4.55 & 2.37 \\
\hline
\end{tabular}

\section{Crowson et al, unpublished data 2005}

Figure 8 Microarray data from five basal cell carcinomas (BCCs) showing upregulated gene transcription vs adjacent normal skin. Several of these genes ie actin-beta, thymosin beta 10 and beta 4 and protein tyrosine kinase 2 (PTK2) all relate to the actin filaments and their assembly into surface attachment plaques. Actin and the actin-attachment plaques are involved in cell motility. Transforming growth factor beta-stimulated protein (TSG22) is upregulated 2.37 times in BCC as opposed to adjacent normal skin. Activation of the smoothened signaling pathway in BCC is associated with upregulated transcription of TGF Beta (see Basal Cell Carcinoma: Biology, Morphology and Clinical Implications elsewhere in this supplement). The COL 3A1 gene for collagen synthesis is upregulated by a factor of 3.4:1 over the adjacent normal tissue and the secreted protein, acidic, rich in cystein (SPARC/osteonectin) gene is upregulated 3.1 times. The latter is involved in cell motility and cell adhesion.

\section{Genes Up Regulated in BCC}

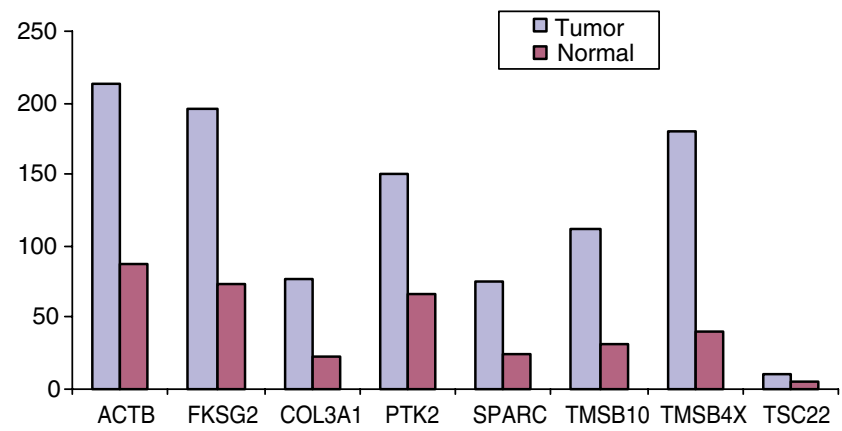

Figure 9 Microarray analysis of basal cell carcinoma. The same data as in Figure 8 is shown in a tabulated form generated by the computer software.

intensive study. In a study of pathways of E2F-1induced apoptosis in melanoma, one group screened 12000 genes to identify those which are upregulated in response to E2F-1, and found 452 genes linked to its overexpresion. Of these, changes in expression of 17 genes was confirmed by realtime PCR analysis. ${ }^{38}$ The mRNA product of a gene linked to the X-linked apoptosis protein (XIAP), termed XIAP factor I was shown to be significantly downregulated in 15 of 16 melanoma lines evaluated, and significantly reduced in tissue microarray of 70 melanomas vs 40 melanocytic nevi. ${ }^{39}$

The main objective of microarray technology as applied to dermatologic neoplasia is to classify neoplasms based upon their molecular profile and to define their biological capacity for metastasis. In addition, the cDNA microarray can also be used to establish the molecular pharmacology of a neoplasm, namely, how a given cancer metabolizes and responds to a particular chemotherapeutic agent. ${ }^{40}$ Better understanding of a tumor's signalling and metabolic pathways could lead to the provision of specific novel therapeutic targets not yet understood. ${ }^{41,42}$ Specific vaccine strategies based upon tumor-derived complementary RNA has been proposed. ${ }^{43}$ These strategies may evolve into the individualized therapy of patients following precise definition of the molecular character of their cancers.

The oligonucleotide microarray uses silicone wafers similar to those employed in the computer industry to precisely identify specific locations and to effect the construction of unique oligonucleotide sequences in a microscopic array. The 


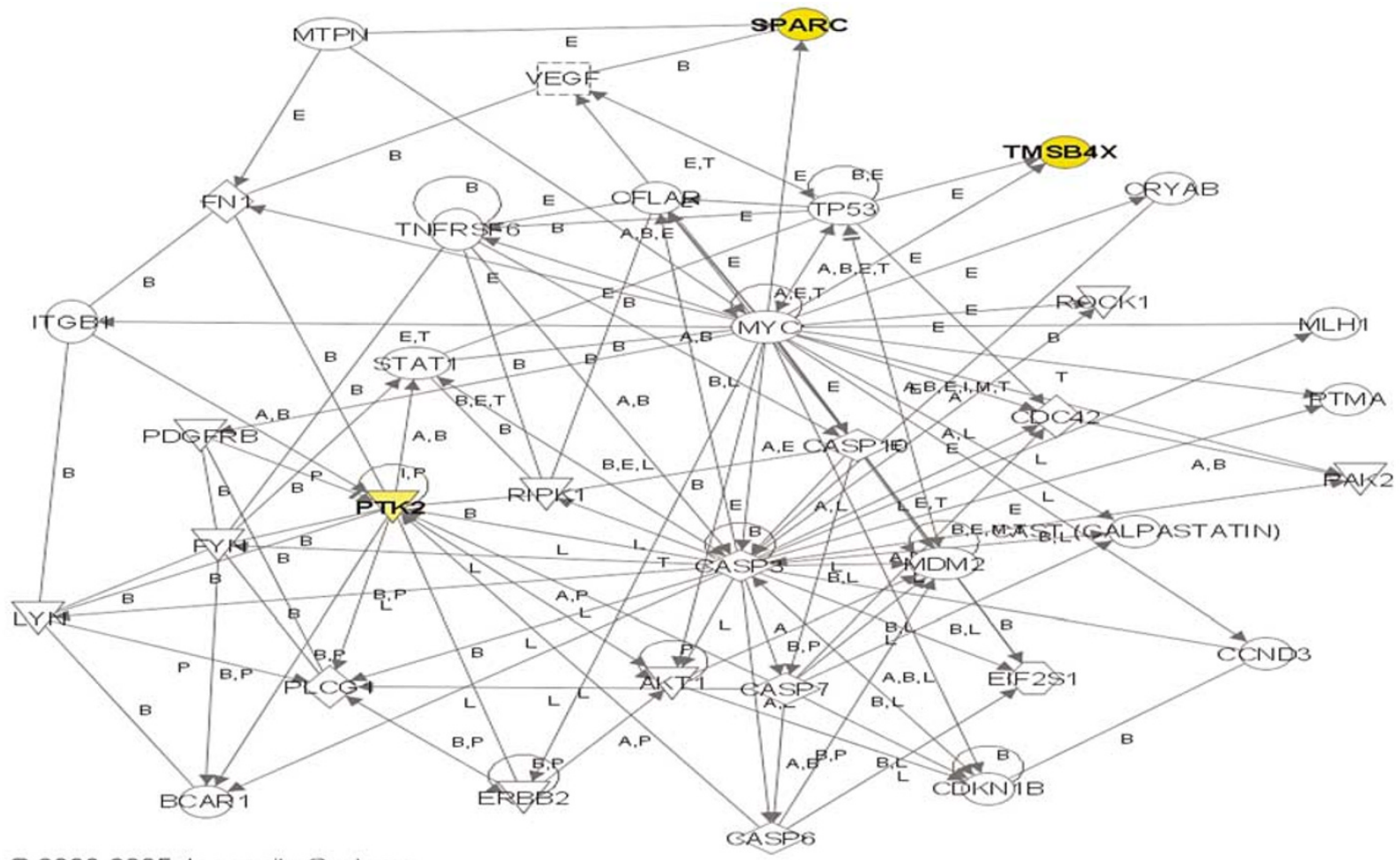

(ㄷ) 2000-2005, Ingenuity Systems
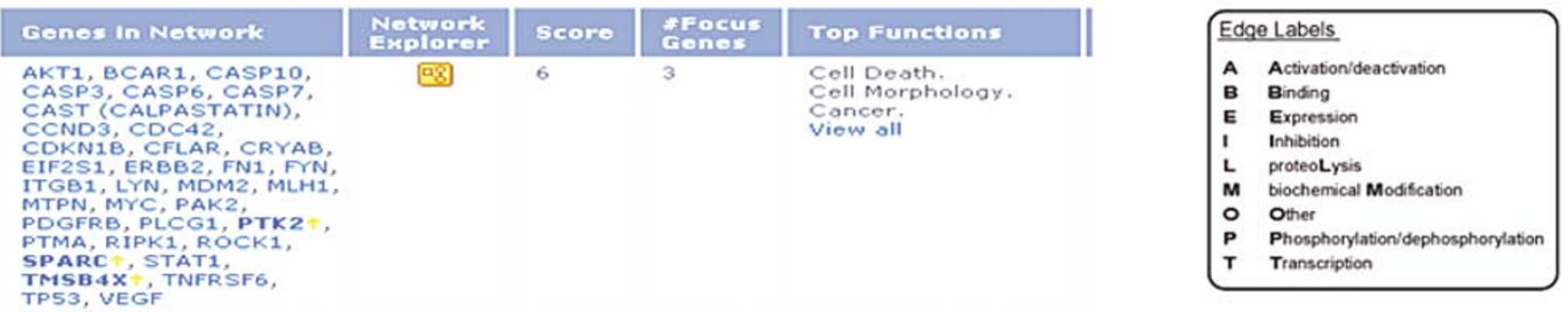

Figure 10 Cluster identification software links three gene clusters involved in cell motility in basal cell carcinoma.

oligonucleotide array is best applied to the search for specific genetic mutations, as a single microchip employing a series of different oligonucleotide sequences can explore for all known mutations of a particular genetic sequence. Affymetrix Corporation (Santa Clara, CA, USA) markets a chip that enables the exploration of every nucleotide of exons 2-11 of the p53 tumor suppressor gene through the assay of 1262 base pairs via the redundant analysis of each of four base pair possibilities at each location. ${ }^{44}$ A second use for the oligonucleotide microarray is that of biopharmacology, where anticancer agent efficacy can be correlated to gene expression in tissue..$^{4,46}$

Complimentary to these novel genomic initiatives is proteomics, the study of expressed proteins in tissue and cell types. ${ }^{47}$ Both proteomic and other tissue microarray studies are enhanced by the use of laser capture microdissection which enables isolation of critical neoplastic cells. ${ }^{48}$ Proteins are the functional products of genes. They are modified by post-translational events such as phosphorylation or glycosylation as well as by environmental or epigenetic factors which impact the aging cell. Proteomic microarrays assay the functional state of the protein products of genes identifiable by cDNA genomic technology.

\section{Conclusion}

Combining proteomic and genomic investigation provides a novel molecular diagnostic strategy for melanoma and other skin neoplasms that will presently lead to new therapeutic strategies. Conventional clinical and histologic (ie morphological) data will remain a necessary adjunct to guide these novel strategies as they evolve.

\section{Acknowledgements}

I am indebted to Dr Laura McIntosh, Director of PreClinical Studies at Advanced Research Technologies 
in Saint-Laurent, PQ, Canada for her enthusiastic guidance of our infrared spectroscopy studies and for review of the first-half of this manuscript. Dr Michael Centola, Director of the Microarray and Genomics Core Facility of the Oklahoma Medical Research Foundation (OMRF), Oklahoma City, OK, USA, supervised the microarray analysis described herein. Both have graciously provided figures for this article. Nelda Stender of Tulsa, OK, provided expert transcription assistance.

\section{References}

1 McIntosh LM, Jackson M, Mantsch HH, et al. Infrared spectra of basal cell carcinomas are distinct from nontumor-bearing skin components. J Invest Dermatol 1999;112:951-956.

2 McIntosh LM, Mansfield JR, Crowson AN, et al. Analysis and interpretation of infrared microscopic maps: visualization and classification of skin components by digital staining and multivariate analysis. Biospectroscopy 1999;5:265-275.

3 McIntosh LM, Mansfield JR, Crowson AN, et al. Classification of infrared spectra from skin tumors. In: Anderson RR et al. (eds). Lasers in Surgery: Advanced Characterization, Therapeutics and Systems Vol. 3907, Proceedings of SPIE, 2000, pp 126-135.

4 McIntosh LM, Jackson M, Mantsch HH, et al. Nearinfrared spectroscopy for dermatological applications. Vibrational Spectrosc 2001;29:53-58.

5 McIntosh LM, Summers R, Jackson M, et al. Towards non-invasive screening of skin lesions by near-infrared spectroscopy. J Invest Dermatol 2001;116:175-181.

6 Mansfield JR, McIntosh LM, Crowson AN, et al. An LDA-guided search engine for the non-subjective analysis of infrared microscopic maps. Appl Spectrosc 1999;53:1323-1330.

7 Deloukas P, Schuler GD, Gyapay G, et al. A physical map of 30000 human genes. Science 1998;282: 744-746.

8 Hogenesch JB, Ching KA, Batalov S, et al. A comparison of the Celera and Ensembl predicted gene sets reveals little overlap in novel genes. Cell 2001;106: 413-415.

9 Spector DL. The dynamics of chromosome organization and gene regulation. Ann Rev Biochem 2003;72: 573-608.

10 Rimm DL. Impact of microarray technologies on cytopathology. Acta Cytologica 2001;452:111-114.

11 Khan J, Bittner ML, Chen Y, et al. DNA microarray technology: he anticipated impact on the study of human disease. Biochem Biophys Acta 1999;1423: M17-M28.

12 Ramaswamy S, Golub TR. DNA microarrays in clinical oncology. J Clin Oncol 2002;20:1932-1941.

13 Cheung VG, Morley M, Aguilar F, et al. Making and reading microarrays. Nat Genet 1999;21(Suppl 1): 15-19.

14 Southern E, Mir K, Shchepinov M. Molecular interactions on microarrays. Nat Genet 1999;21(Suppl 1): 5-9.

15 Lipshutz RJ, Fodor SPA, Gingeras TR, et al. High density synthetic oligonucleotide arrays. Nat Genet 1999;21(Suppl 1):20-24.
16 Loftus SK, Chen Y, Gooden G, et al. Informatic selection of a neural crest-melanocyte cDNA set for microarray analysis. Proc Natl Acad Sci USA 1999;96: 9277-9280.

17 Sherlock G, Hernandez-Boussard T, Kasarskis A, et al. The Stanford microarray database. Nucl Acids Res 2001;29:152-155.

18 Sellheyer K, Belbin TJ. DNA microarrays: from structural genomics to functional genomics. The applications of gene chips in dermatology and dermatopathology. J Am Acad Dermatol 2004;51:681-692.

19 Kim S, Dougherty ER, Bittner ML, et al. General nonlinear framework for the analysis of gene interaction via multivariate expression arrays. J Biomed Opt 2000;5:411-424.

20 Heiskanen MA, Bittner ML, Chen Y, et al. Detection of gene amplification by genomic hybridization to cDNA microarrays. Cancer Res 2000;60:799-802.

21 Bittner M, Meltzer P, Chen Y, et al. Molecular classification of cutaneous malignant melanoma by gene expression profiling. Nature 2000;406:536-540.

$22 \mathrm{Su}$ YA, Bittner ML, Chen Y, et al. Identification of tumor-suppressor genes using human melanoma cell lines UACC903, UACC903 (+6), and SRS3 by comparison of expression profiles. Mol Carcinogen 2000;28: 119-127.

23 Seykora JT, Jih D, Elenitsas R, et al. Gene expression profiling of melanocytic lesions. Am J Dermatopathol 2003;25:6-11.

24 Kim CJ, Reintgen DS, Yeatman TJ. The promise of microarray technology in melanoma care. Cancer Control 2002;9:49-53.

25 Baldi A, De Luca A, Morini M, et al. The HtrA1 serine protease is down-regulated during human melanoma progression and represses growth of metastatic melanoma cells. Oncogene 2002;21:6684-6688.

26 Baldi A, Battista T, De Luca A, et al. Identification of genes down-regulated during melanoma progression: a cDNA array study. Exp Dermatol 2003;12:213-218.

27 Carr KM, Bittner M, Trent JM. Gene-expression profiling in human cutaneous melanoma. Oncogene 2003; 22:3076-3080.

28 McDonald SL, Edington HD, Kirkwood JM, et al. Expression analysis of genes identified by molecular profiling of VGP melanomas and MGP melanomapositive lymph nodes. Cancer Biol Ther 2004;3: 110-120.

29 Alonso SR, Ortiz P, Pollan M, et al. Progression in cutaneous malignant melanoma is associated with distinct expression profiles: a tissue microarray-based study. Am J Pathol 2004;164:193-203.

30 Wang E, Marincola FM. cDNA arrays and the enigma of melanoma immune responsiveness. Cancer J 2001;7: 16-24.

31 Weeraratna AT, Jiang Y, Hostetter G, et al. Wnt5a signaling directly affects cell motility and invasion of metastatic melanoma. Cancer Cell 2002;1:279-288.

32 Czubayko F, Schulte AM, Berchem GJ, et al. Melanoma angiogenesis and metastasis modulated by ribozyme targeting of the secreted growth factor pleiotrophin. Proc Natl Acad Sci USA 1996;93:14753-14758.

33 Seftor RE, Seftor EA, Koshikawa N, et al. Cooperative interactions of laminin 5 gamma2 chain, matrix metalloproteinase-2, and membrane type-1-matrix metalloproteinase are required for mimicry of embryonic vasculogenesis by agressive melanoma. Cancer Res 2001;61:6322-6327. 
34 De Wit NJW, Burtscher HJ, Weidle UH, et al. Differentially expressed genes identified in human melanoma cell lines with different metastatic behaviour using high density oligonucleotide arrays. Melanoma Res 2002;12:57-69.

35 Kunz M, Moeller S, Koczan D, et al. Mechanisms of hypoxic gene regulation of angiogenesis factor Cyr61 in melanoma cells. J Biol Chem 2003;278: 45651-45660.

36 Kononen J, Bubendorf L, Kallioniemi A, et al. Tissue microarrays for high-throughput molecular profiling of tumor specimens. Nat Med 1998;4:844-847.

37 Mirmohammadsadegh A, Baer A, Nambiar S, et al. Rapid identification of dysregulated genes in cutaneous malignant melanoma metastases using cDNA technology. Cells Tissues Organs 2004;177:119-123.

38 Jamshidi-Parsian A, Dong Y, Zheng X, et al. Gene expression profiling of E2F-1-induced apoptosis. Gene 2005;344:67-77.

$39 \mathrm{Ng}$ KC, Campos EI, Martinka M, et al. XAF1 expression is significantly reduced in human melanoma. J Invest Dermatol 2004;123:1127-1134.

40 Scherf U, Ross DT, Waltham M, et al. A gene expression database for the molecular pharmacology of cancer. Nat Genet 2000;24:236-244.

41 Roses AD. Pharmacogenetics and future drug development and delivery. Lancet 2000;355:1358-1361.
42 Brugarolas J, Haynes BF, Nevins JR. Towards a genomic-based diagnosis. Lancet 2001;357:249-250.

43 Carralot JP, Weide B, Schoor O, et al. Production and characterization of amplified tumor-derived cRNA libraries to be used as vaccines against metastatic melanomas. Genet Vaccines Ther 2005;3:6.

44 Wikman FP, Lu MI, Thykjaer T, et al. Evaluation of the performance of a p53 sequencing microarray chip using 140 previously sequenced bladder tumor samples. Clin Chem 2000;46:1555-1561.

45 Butte AJ, Tamayo P, Slonim D, et al. Discovering functional relationships between RNA expression and chemotherapeutic susceptibility using relevance networks. Proc Natl Acad Sci USA 2000;97:1218212186.

$46 \mathrm{Hu}$ JS, Durst M, Kerb R, et al. Analysis of drug pharmacology towards predicting drug behaviour by expression profiling using high-density oligonucleotide arrays. Ann NY Acad Sci 2000;919:9-15.

47 Banks RE, Dunn MJ, Hochstrasser DF, et al. Proteomics: new perspectives, new biomedical opportunities. Lancet 2000;356:1749-1756.

48 Banks RE, Dunn MJ, Forbes MA, et al. The potential use of laser capture microdissection to selectively obtain distinct populations of cells for proteomic analysis-preliminary findings. Electrophoresis 1999; 20:689-700. 